\title{
Analysis of the Efficiency of Teaching Chess in Schools
}

\author{
Ruben Mirzakhanyana, Srbuhi Gevorgyana, Vahan Sargsyana, Hayk Daveyana
}

\begin{abstract}
The Republic of Armenia, as a world superpower in chess, is engaged in continuous development and implementation of specific strategic programmes which are aimed not only at providing high achievements in chess, but also at: (1) modernizing the educational sphere in the Republic of Armenia; (2) increasing the quality indexes of chess education-as a basic resource in the context of global educational system; (3) considerably deepening education subjects' cognitive interests towards education through the possibilities provided by chess; (4) developing learners' educational-cognitive motivation; and (5) creating conditions for activating learners' mental potential and the abilities to expose them, as well as promoting the awareness of the social value of chess in interpersonal relations. The contextual factors of teaching and learning chess in primary schools of Republic of Armenia have been revealed and presented in this paper. A number of conclusions and recommendations for policy makers are considerably made based on analysis of big research data.
\end{abstract}

\section{Keywords}

Education, research, school, chess

The process of widening and enriching the modern teaching technologies and innovative IT resources throughout the world has opened up new opportunities for promoting the formation of professional and personal competences, in particular, on the basis of the headway of new methods and ways of teaching, and widening the underlying guidelines of educational activities. Nevertheless, because of either scarce, limited potential, insufficient executive efforts made or utterly complicated and persistently revised and changed procedures, the schemes of efficient teaching/learning models at certain time hindered or slowed down the implementation of the cognitive, executive, and operational constituents of perception, understanding, and assimilation in teaching/learning. This is evidenced in a variety of researches published in different countries on the difficulties and typological analyses in the realm of education.
Since 2011, chess, as an academic discipline, is included in the education curriculum in the Republic of Armenia. The current relevance of teaching chess to children derives from the respective explorations into efficient methods aimed at the intellectual development of primary school children. The aim is to develop teaching and students' cognitive realm, in particular, logical thinking, imagination, analytical capacity, thus, contributing to the learning of other school subjects. The idea of using chess for the formation and development of children's intellectual capacity has for a long time been submitted to

aArmenian State Pedagogical University named after Khachatur Abovyan, Armenia

\section{Correspondent Author:}

Srbuhi Gevorgyan, Tigran Mets Ave. 17, Yerevan, Armenia 
experiment-based testing. The Chess Educational Research Center was founded at Armenian State Pedagogical University named after Khachatur Abovyan in 2015. The Center has been developing its activities through the respective teams of psychologists and sociologists. The researchers were enthusiastically engaged to prove the impact of chess on primary school pupils. Consequently, they have recorded a number of positive aspects of chess teaching, despite the numerous difficulties they faced. The experimental studies were carried out in order to overcome the difficulties which emerged between pupils and teachers while teaching chess.

In teaching chess, we come across a variety of problems stemming from both objective and subjective factors. The current circumstances that we face in the education system attribute a particular degree to the aforementioned difficulties which find their expression in the paradigms of subjects, pedagogical-methodological philosophy, psychology, and other realms. In our current conditions, in the educational system, the difficulties take harder characteristics, which are displayed as material, pedagogical-methodical, psychological issues.

The continuous development of the quality of teaching/learning chess in schools requires assessment of the contextual factors which have meaningful impact on the quality of chess education at school. Therefore, one of research priorities of Chess Educational Research Center has been the investigation of the educational progress of learning chess at school. The investigators believe that the respective data collected would be important for research-based decision making related to in-school chess educational policy.

The former studies reveal the impact of chess on the development of meta-cognitive ability and math problem-solving ability among students at different levels of education (Kazemi, Yektayar, and Abad 2011). On the other hand, there was no evidence that might indicate the impact of contextual factors of education on the level of chess skills gained within learning chess in schools nationwide.

The first research aim is to reveal the context-driven and context-based factors influencing school teaching of chess.

\section{THE METHODOLOGY APPLIED}

There are two major dimensions underlying this research:

(1) The first one derives from the very context of chess education. The context-based and context-driven factors covered in the research are identical to the factors defined in TIMSS (Trends in International Mathematics and Science Study) 2011.

The set of dimensions of contextual factors are:

(a) Socio-cultural context;

(b) School context;

(c) In-class/contact hour context;

(d) Context of pupils' characteristics and attitudes.

(2) The second dimension that the research comprises is the level of knowledge of chess. In the course of research, a test was designed on the basis of the school program of chess education (targeting from the 2 nd grade to the 4 th grade pupils). The test evaluates the level of knowledge of chess together with the respective cognitive skills based on learning taxonomy. Thus, the test is based on three domains as follows:

(a) The domain of knowledge that comprises the notions and processes that must be mastered by school children;

(b) The domain of application that is aimed at evaluating the skills of applying knowledge or ideas for answering questions or solving problems;

(c) The domain of reasoning that stems from simple problem-solving spheres involving unfamiliar situations, complete contexts, and problems.

Every single task refers to every single content-based component and cognitive competence 
necessary for completing the assignment given.

Every section of the test involves certain content-based item on chess that appears on teaching/learning schedule among the 2nd-4th grade pupils.

The research participants were 5th-grade students $(\mathrm{N}=500)$, their parents $(\mathrm{N}=500)$, and school teachers of chess $(\mathrm{N}=38)$.

Convenience sampling approach has been carried out based on TIMSS-2011 sampling (Mullis et al. 2009). The sampling covers all the regions of the Republic of Armenia (see Figure 1). The representativeness of respondent group is validated through preliminary pilot research. The percentage of participants involved is illustrated bellow.

The chess achievement evaluation test consists of the sections introduced in teacher's manual (Tumanyan 2011-2013):

(1) Chess board;

(2) The types of figures, names, and actions;

(3) Checkmate and stalemate;

(4) Strategy, end of the game.

In order to give correct answers, students must be acquainted with the content of chess course and must be able to implement cognitive skills as well.

\section{RESEARCH RESULTS}

Figure 2 explains the complexity of items used in the test. As we can see from the results, some of the items are too difficult for students. That is why the line on the diagram is falling down.

The survey revealed that some tasks in achievement evaluation test and school handbook are too difficult and not quite obtainable for most of schoolchildren who learn chess on regular basis.

The results of correlational research allow to state that there are many meaningful correlations between chess achievement level and contextual factors, e.g. lesson preparation conditions, pupils' integration level during chess lessons, students' school motivation, etc. (see Table 1). On the other hand, the skill to achieve checkmate in two moves is correlated with teachers' pedagogical impact during chess lessons.

One of the research questions was formulated as it follows: Which are the positive aspects of teaching chess at school from stakeholders' perspectives? The answers are introduced in the respective proportions in the pie chart below (see Figure 3).

\section{DISCUSSION OF THE RESULTS}

Analyzing the results, we uncovered some lawful key relationships that will further be discussed within the context of possible solutions.

Chess is mostly referred to as a positive factor for pupils' personal development. Our findings help us to state that logical thinking, memory, attention, and self-control characteristics are mostly being developed during chess lessons. Nevertheless, these characteristics still need deeper testing in order to understand the interactions between them within different subjects. So, the specific key factors must be implemented in school program of chess. Assignments and tasks should be in line with the expected outcomes-such as cognitive development, personality, moral characteristics, etc.

The teachers' pedagogical impact and attitudes towards education for all are also considerably required for effective chess education in primary schools. Pedagogy, inclusive practices, educational psychology, and chess teaching methodology must be embraced to cover the necessary competence matrix for future chess teachers. Accordingly, the curriculum mapping for chess teachers' education program has been designed by the methodological group of the Center of Chess Educational Research of Armenian State Pedagogical University.

As evidenced above, parents' appropriate support, family conditions, and parental educational level are most frequently expressed contextual factors for adequate implementation of chess in schools. Thus, 


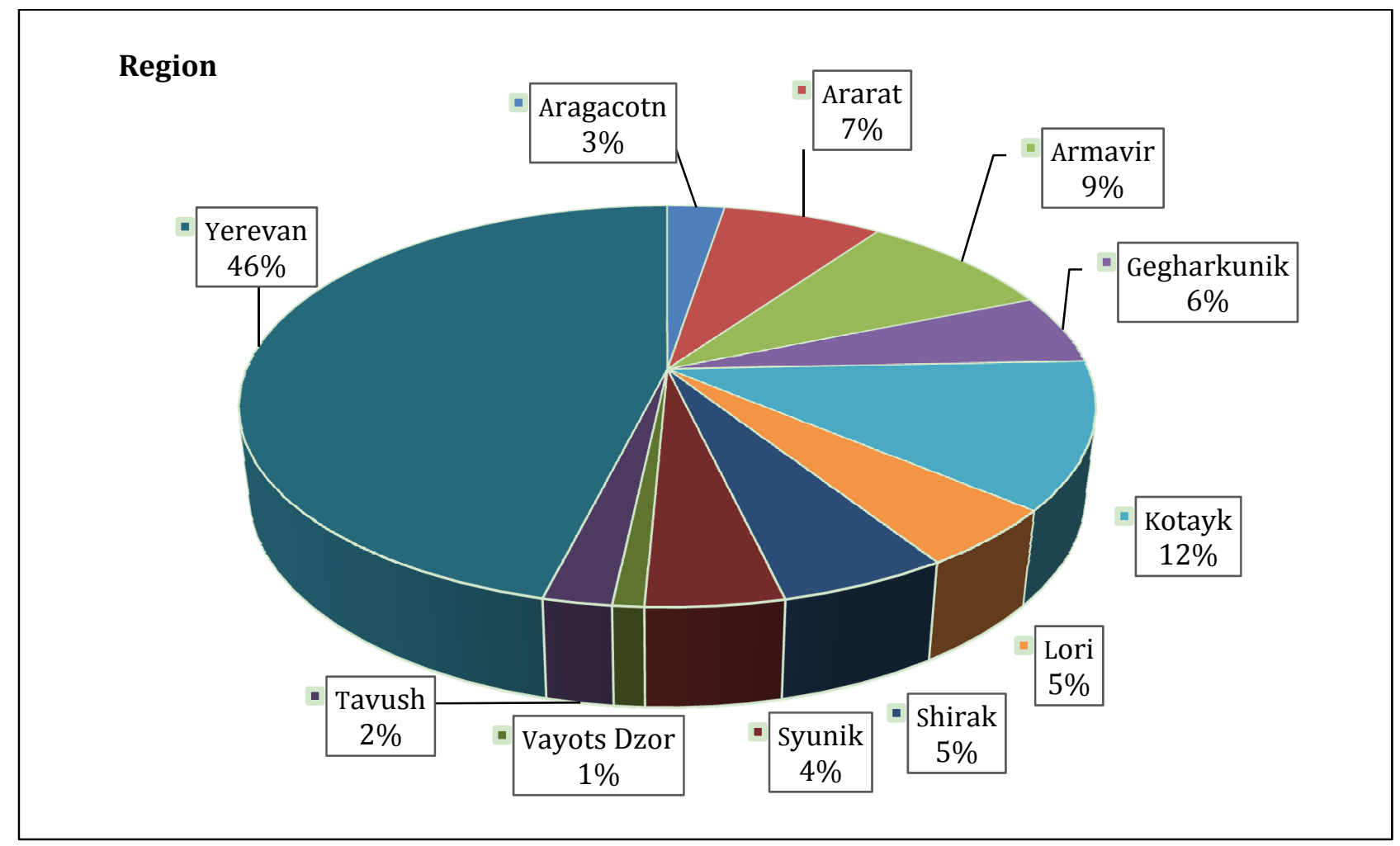

Figure 1. Sampling of Participants.

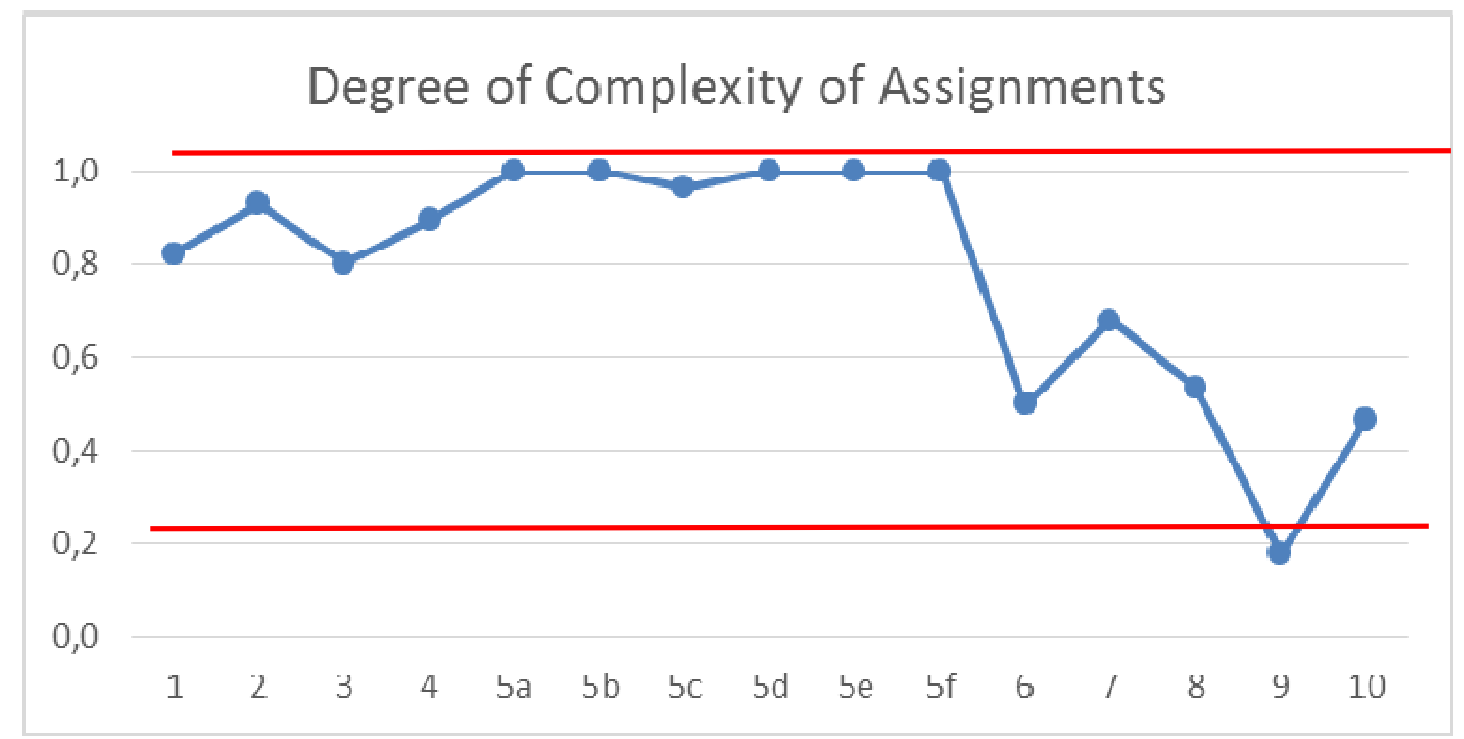

Figure 2. Degree of Complexity of Assignments. 
Table 1. Inter-correlational Matrix of Contextual Factors and Chess Achievement Evaluation Test Scores $(\mathrm{P} \leq .05)$

\begin{tabular}{|c|c|c|c|c|c|c|c|c|c|c|c|}
\hline Correlational factors & 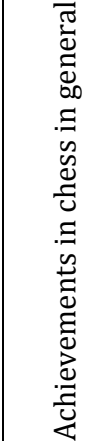 & 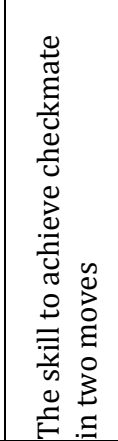 & 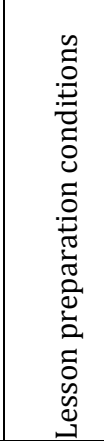 & 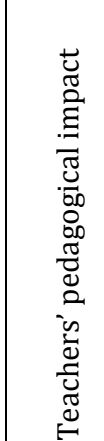 & 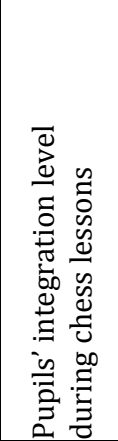 & 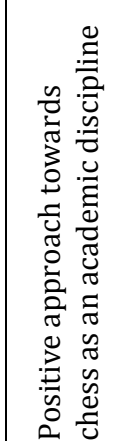 & 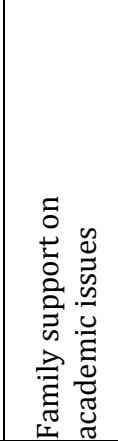 & 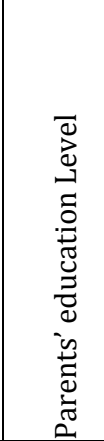 & 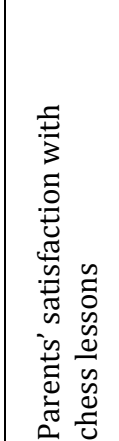 & 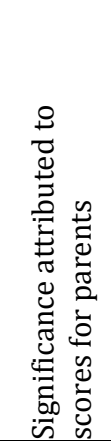 & 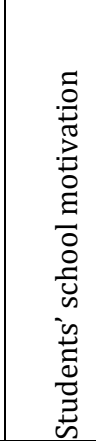 \\
\hline $\begin{array}{l}\text { Achievements in chess } \\
\text { in general }\end{array}$ & 1.000 & & $\begin{array}{l}.545 \\
.632^{1} \\
.646^{2}\end{array}$ & & .728 & & & & & & .635 \\
\hline $\begin{array}{l}\text { The skill to achieve } \\
\text { checkmate in two } \\
\text { moves }\end{array}$ & & 1.000 & & .654 & & & & & & & \\
\hline $\begin{array}{l}\text { Lesson preparation } \\
\text { conditions }\end{array}$ & $\begin{array}{l}.545 \\
.632 \\
.646 \\
\end{array}$ & & 1.000 & & & & & $\begin{array}{l}.709 \\
.449\end{array}$ & & & \\
\hline $\begin{array}{l}\text { Teachers' pedagogical } \\
\text { impact }\end{array}$ & .923 & 0,654 & & 1.000 & & & & & & & \\
\hline $\begin{array}{l}\text { Pupils' integration } \\
\text { level during chess } \\
\text { lessons }\end{array}$ & .728 & & & & 1.000 & & & & & & \\
\hline $\begin{array}{l}\text { Positive approach } \\
\text { towards chess as an } \\
\text { academic discipline }\end{array}$ & & & & & & 1.000 & .577 & & & & \\
\hline \begin{tabular}{|l} 
Family support on \\
academic issues
\end{tabular} & & & & & & .577 & 1.000 & & 417 & & \\
\hline \begin{tabular}{|l} 
Parents' education \\
level
\end{tabular} & & & & & & & & 1.000 & & -.372 & \\
\hline \begin{tabular}{|l|} 
Parents' satisfaction \\
with chess lessons \\
\end{tabular} & & & & & & & .417 & & 1.000 & & \\
\hline \begin{tabular}{|l|} 
Significance attributed \\
to scores for parents
\end{tabular} & & & & & & & & -.372 & & 1.000 & \\
\hline \begin{tabular}{|l|} 
Students' school \\
motivation
\end{tabular} & .635 & & & & & & & & & & 1.000 \\
\hline
\end{tabular}

Notes: ${ }^{1}$ Number of books. ${ }^{2}$ Own room for lesson preparation. Significance of presented values $p>.05$. 


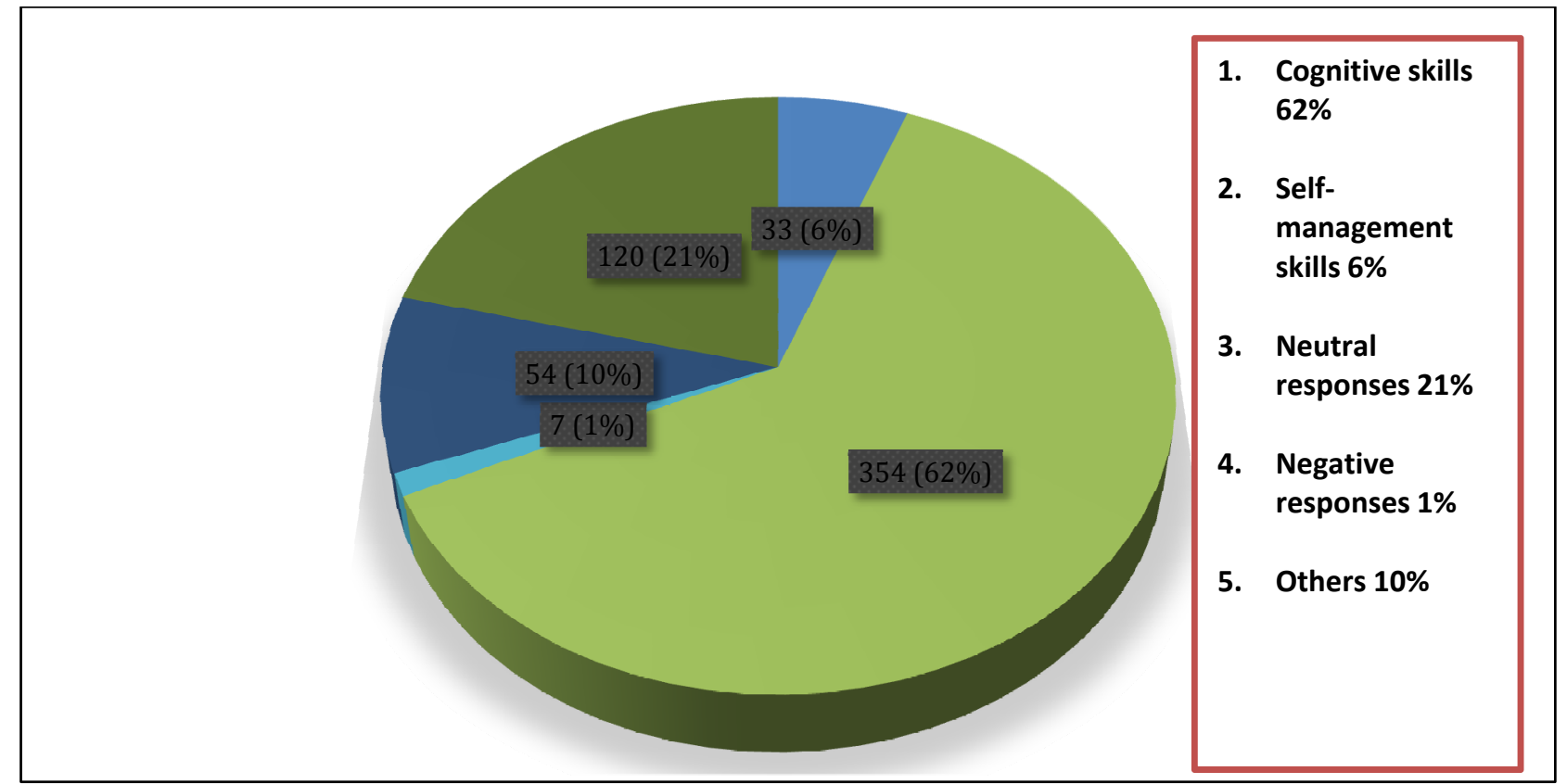

Figure 3. Parents' and Teachers' Attributions of Impact of Chess on Pupils' Development.

the quality of school and parents cooperation should be improved which is already planned in on-line course for chess teachers. It has become transparent that school program of chess and its implementation do depend on parents' background level and their support which allows concluding that school program must focus on tasks which will mostly provide learning at school with less after-class assignments and homework.

The chess achievement evaluation test developed on the basis of primary school chess curricula should be improved by taking into consideration the following aspects:

(1) The results must be compared with other tools which are developed worldwide, which, consequently, assumes an international adaptation of test;

(2) As far as pupils' cognitive and other psychological skills, they are among expected outcomes of primary chess curricula, and some tasks related to cognitive skills are to be tested as well;

(3) The results of chess achievement evaluation test's validation must accordingly be compared with children's school performance.

In primary school chess teaching/learning curricula, the respective educational materials must be submitted for further improvement and enhancement in several ways:

(1) The pertinent educational triangle should be designed in accordance with the relevant concord between learning outcomes and teaching/learning methods, as well as, assessment tasks and techniques. These three components must be mutually responsive;

(2) The materials of teaching/learning chess have to be introduced in a more facilitated way. As stated above, it should be kept and delivered in smart and stupid-simple ways;

(3) Teaching and learning materials for primary school chess curricula must be improved in line with instructional principles such as providing models, presenting materials in small steps, checking students' understanding, covering large number of students and involving all students, providing equality of teaching materials in terms of students' knowledge and skills, connecting new material with prior learning, etc. 


\section{CONCLUSIONS}

Summarizing the results of this research, we may conclude that:

(1) Chess as an academic discipline is mostly referred to as a positive factor for pupils' personal development;

(2) Parents' educational level is one of the frequently expressed contextual factors for sufficient implementation of chess in schools;

(3) Chess achievement evaluation test should be improved based on the results of current research: Some curricular changes in school program of chess might necessarily be introduced;

(4) The decent support by parents and family conditions for students' lesson preparation are also among the priorities and key factors for successful implementation of chess in school curricula: This area should be analyzed deeper to understand the ways and possibilities of schools for enhancing the quality of learning;

(5) Teachers' pedagogical impact and attitudes towards education for all are also considerably demanded for effective chess education in primary schools.

The research findings will allow the respective staff to disseminate good practices and to explore into the weak points at different levels of education planning ranging from national to student's (individual) level.

\section{References}

Anderson, L. and D. Krathwohl. 2001. A Taxonomy for Learning, Teaching and Assessing: A Revision of Bloom's Taxonomy of Educational Objectives. New York: Longman.

Chess in Schools: Evaluation Report and Executive Summary. 2016. Institute of Education, UCL, London.

Ferguson, R. 1986. "Developing Critical and Creative Thinking
Through Chess." Report on ESEA Title IV-C Project. Presented at the Annual Conference of the Pennsylvania Association for Gifted Education, Pittsburgh, Pennsylvania.

Karapetyan, V., S. Gevorgyan, and R. Petrosyan. 2015. "Target-Oriented Research of the Strategic Programmes on Chess Activities as Specialized Experimental Platform for Dynamic Development of Public Education." Presented at the 7th World Conference on Educational Sciences (WCES-2015), February 5-7, 2015, Novotel Conference Center, Athens, Greece.

Kazemi, F., M. Yektayar, and A. M. B. Abad. 2011. "Investigation the Impact of Chess Play on Developing Meta-cognitive Ability and Math Problem-Solving Power of Students at Different Levels of Education." Presented at the 4th International Conference of Cognitive Science (ICCS 2011).

Mullis, I. V. S., M. O. Martin, G. J. Ruddock, C. Y. O'Sullivan, and C. Preuschoff. 2009. TIMSS 2011 Assessment Frameworks. Boston, MA: TIMSS \& PIRLS International Study Center, Lynch School of Education, Boston College. Tumanyan, H. 2011-2013. Teacher Handbook. Armenia.

\section{Bios}

Ruben Mirzakhanyan, Ph.D. in historical sciences, professor of the Chair of Armenian History, chancellor of Khachatur Abovian Armenian State Pedagogical University Chair of Academic Council, Armenian State Pedagogical University named after Khachatur Abovyan, Yervan, Armenia; research fields: modern period of the history of Armenia, history of Armenian culture, history of Armenian visual arts.

Srbuhi Gevorgyan, Ph.D. in psychology, professor, Armenian State Pedagogical University named after Khachatur Abovyan, Yervan, Armenia; research fields: social psychology, communication psychology, age and pedagogical psychology.

Vahan Sargsyan, Ph.D. in psychology, associate professor, head of Chess Educational Research Center at Armenian State Pedagogical University named after Khachatur Abovyan, Yervan, Armenia; research fields: educational psychology, social psychology.

Hayk Daveyan, MA in psychology, study educational measurement and educational psychology at National Center of Educational Technologies, Armenian State Pedagogical University named after Khachatur Abovyan, Yervan, Armenia; research fields: educational psychology, educational assessment, QA in eduction. 